\title{
PERBEDAAN TEKANAN DARAH PADA PASIEN CKD SEBELUM DAN SETELAH HEMODIALISIS DI RUANG HEMODIALISARS SWASTA DI SULAWESI UTARA
}

\author{
Yanti Rosalina Pasaribu ${ }^{a}$, Sefti S.J. Rompas ${ }^{b}$, Rina Margaretha Kundre

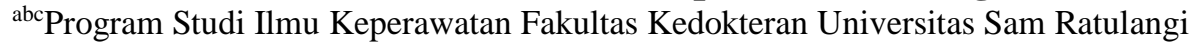 \\ Email :yantirosapasaribu@gmail.com
}

\begin{abstract}
Background:CKD is a progressive and irreversible kidney function disorder in which the body fails to maintain metabolism and fluid-electrolyte balance, causing urinary retention and other nitrogenous wastes in the blood. The purpose of this study was to determine the difference in blood pressure in CKD patients before and after hemodialysis at General Hospital GMIM Bethesda Tomohon. Methods: The type of research used is analytic observational with a cross sectional design, data analysis using the Wilcoxon Signed Ranks Test technique. Samples were taken using Total Sampling. The number of samples is 40 respondents. Instruments The data collection in this study used an observation sheet. Results: the study showed the significance level of the $Z$ value (-3.091) and significant $(p=0.002<\alpha=$ 0.05). Conclusion: Therefore, the results of this study indicate that there is a difference in blood pressure in CKD patients before and after hemodialysis.
\end{abstract}

Keywords: Blood Pressure, CKD, Hemodialysis

\begin{abstract}
Abstrak
Latar Belakang:Gagal Ginjal Kronik (GGK) merupakan gangguan fungsi ginjal yang progressif dan irreversible dimana tubuh gagal untuk mempertahankan metabolism dan keseimbangan cairan elektrolit, menyebabkan retensi urin dan sampah nitrogen lain dalam darah. Tujuandaripenelitianiniadalahuntukmengetahui perbedaan tekanan darah pada pasien CKD sebelum dan setelah hemodialysis di RSU GMIM Bethesda Tomohon. Metode: Jenis penelitian yang digunakan adalah observasional analitikdengan rancangancross sectional, analisis data menggunakan teknik uji Wilcoxon Signed Ranks Test.Sampel diambil dengan menggunakan Total Sampling. Jumlah sampel adalah 40 responden. Instrumen Pengumpulan data pada penelitian ini menggunakan lembar observasi. Hasil:penelitian menunjukkan tingkat kemaknaan nilai Z $(-3,091)$ dan nilai $\mathrm{p}=0,002(\mathrm{p} \leq 0,05)$. Kesimpulan: Hasil penelitian menunjukkan terdapatadaperbedaan tekanan darah pada pasien CKD sebelum dan setelah hemodialisis.
\end{abstract}

Kata Kunci : Tekanan Darah, Gagal Ginjal Kronik, Hemodialisis. 


\section{PENDAHULUAN}

Ginjal merupakan organ utama sistem perkemihan. Ginjal mempunyai peranan penting dalam menjaga kesehatan tubuh secara keseluruhan karena ginjal salah satu organ vital dalam tubuh. Ginjal dianggap mengalami kegagalan secara mendadak ketika ginjal tersebut tidak bisa berfungsi secara mendadak. Jadi ginjal merupakan organ vital dalam tubuh yang berfungsi mempertahankan homeostatis tubuh, dimana ginjal mengalami kegagalan menjalankan fungsinya dapat mengakibatkan penumpukan cairan tubuh dan uremia (Cahyaningsih, 2011).

Gagal ginjal kronis (chronic renal failure) atau sering disebut dengan CKD (Chronic Kidney Desease) adalah kerusakan ginjal progresif yang berakibat fatal dimana kemampuan tubuh gagal untuk mempertahankan metabolisme dan keseimbangan cairan dan elektrolit, menyebabkan azotemia (retensi urea dan sampah nitrogen lain dalam darah). Penyakit ini juga dikenal dengan penyakit ginjal tahap akhir (End Stage Renal Desease).Angka kejadian ESRD sangat tinggi, di Amerika sendiri sudah mencapai $8 \%$ pertahun dalam 5 tahun terakhir dimana 300.000 pasien perlu perawatan di rumah sakit (Diyono \& Sri, 2019).

Gagal ginjal kronik merupakan gangguan fungsi ginjal yang progresif dan irreversibel dimana tubuh gagal untuk mempertahankan metabolisme dan keseimbangan cairan elektrolit, menyebabkan retensi urin dan sampah nitrogen lain dalam darah (Muttaqin \&Kumala, 2011).

Hasil Riskesdas (2018) mengatakan bahwa jumlah penderita di Indonesia sendiri mengalami kenaikan dari $2 \%$ mencapai $3,8 \%$ pada tahun 2018 dari jumlah penduduk Indonesia hanya $19,3 \%$ dari pasien gagal ginjal kronis tersebut menjalani terapi dialisis. Bila seseorang mengalami penyakit gagal ginjal kronik sampai pada stadium 5 atau telah mengalami penyakit ginjal kronik (gagal ginjal) dimana laju filtrasi glomerulus (15 $\mathrm{ml} / \mathrm{menit}$ ) ginjal tidak mampu lagi menjalankan seluruh fungsinya dengan baik maka dibutuhkan terapi untuk menggantikan fungsi ginjal. Sekitar 1,5 juta orang harus menjalani hidup bergantung pada cuci darah.

Hemodialisis adalah terapi pada pasien GGK stadium 5 yang paling banyak digunakan di Indonesia. Proses hemodialisis di Indonesia paling banyak dilakukan sebanyak 2 kali per minggu pada umumnya memerlukan waktu selama 4-5 jam. Salah satu komponen yang digunakan dalam proses hemodialisis yakni dialisis. Dialisis merupakan cairan yang membantu mengeluarkan sampah uremik dan juga dapat menggantikan substansi yang dibutuhkan tubuh seperti natrium (Cahyaningsih, 2011). Bagi penderita Gagal Ginjak Kronik, hemodialysis akan mencegah kematian tetapi tidak dapat menyembuhkan atau memulihkan fungsi ginjal secara keseluruhan. Hemodialisis dilakukan untuk mengeluarkan sisa-sisa metabolisme atau racun tertentu dari peredaran darah manusia, seperti kelebihan ureum, kreatinin, asam urat dan zat-zat lain melalui membran semipermeabel. Pasien gagal ginjal kronik menjalani proses hemodialisis sebanyak 2-3 kali seminggu, dimana setiap kali hemodialisis rata-rata memerlukan waktu antara 4-5 jam (Rahman, Kaunang \& Elim, 2016).

Tekanan darah merupakan faktor resiko utama penyakit kardiovaskular yang mortalitasnya meningkat sampai 20 kali lipat pada pasien penyakit gagal ginjal kronis yang menjalani hemodialisis.

Studi pendahuluan yang dilakukan oleh peneliti di Ruang Hemodialisa RSU GMIM Bethesda Tomohon pada bulan Agustus September tahun 2018 didapatkan bahwa pasien yang melakukan tindakan hemodialisa berjumlah 40 orang dan menjadi penyebab adalah Gagal Ginjal 
Kronik, rata-rata kunjugan pasien 10 orang per hari.

Berdasarkan hasil pengamatan studi pendahuluan didapati juga pasien yang menjalani Hemodialisa relatif ada yang mengalami peningkatan atau penurunan tekanan darah pada saat menjalani tindakan hemodialisa.

Berdasarkan latar belakang diatas penelitianini bertujuan untukmenganalisis perbedaan tekanan darah pada pasien CKD sebelum dan setelah hemodialysis.

\section{METODE PENELITIAN}

Dalam penelitian ini, peneliti menggunakan desain adalah observasional analitik dengan rancangan penelitian Cross Sectional yaitu data yang menyangkut variable independen dan variabel dependen akan dikumpulkan dalam waktu yang bersamaan (Notoatmodjo, 2012).
Populasi dan Sampel pada penelitian ini adalah 40 orang pasien diambil dari data kunjungan 3 bulan terakhir di ruang Hemodialisa RSU GMIM Bethesda Tomohon, yang diambil dengan menggunakan metode Total Sampling yaitu jumlah sampel dengan jumlah populasi 40 orang. Instrumen penelitian yang digunakan untuk pengumpulan data dalam penelitian ini berupa lembar observasi(inisial pasien, jenis kelamin,umur dan hari/tanggal). Pengolahan data menggunakan uji Wilcoxon Signed Ranks Text dan pengolahan data dengan bantuan program komputer. Penelitian ini telah dilakukan dengan standar etika penelitian yang ada yaitu, informasi untuk responden, kerahasiaan identitas, dan kerahasiaan informasi.Penelitian ini telah mendapat izin dari Instalasi Hemodialisa RS Swasta di Sulawesi Utara tempat dilakukan penelitian dengan nomor izin 605/RSB/M/VI/2019

\section{HASIL dan PEMBAHASAN}

\section{A. HASIL}

\section{Karakteristik Responden}

Tabel 1. Distribusi Frekuensi Menurut Karakteristik Responden

\begin{tabular}{ccc}
\hline Karakteristik & Kategori & $\%$ \\
\hline Usia & $36-44$ tahun & 5 \\
& $45-59$ tahun & 55 \\
& $60-74$ tahun & 40 \\
\hline \multirow{2}{*}{ Jenis Kelamin } & Laki-Laki & 57,5 \\
& Perempuan & 42,5 \\
\hline Total & 40 & 100
\end{tabular}

\section{Sumber: Data Primer, 2019}

Hasil penelitian berdasarkan tabel di atas menunjukkan bahwa sebagian besar sampel memiliki usia $60-74$ tahun sebanyak 16 orang (40\%), usia 45 - 59 tahun sebanyak 22 orang $(55 \%)$, dan yang sedikit usia $36-$
44 tahun sebanyak 2 orang (5\%). Sedangkan responden dengan jenis kelamin laki-laki yaitu sebanyak 23 orang $(57,5 \%)$ dan sisanya berjenis kelamin perempuan yaitu 17 orang $(42,5 \%)$. 


\section{Analisa Univariat}

Tabel 2. Distribusi sampel tekanan darah sebelum hemodialisis dan sampel tekanan darah sesudah hemodialisis

\begin{tabular}{clllll}
\hline Tekanan Darah & \multicolumn{3}{c}{ Sebelum } & \multicolumn{2}{c}{ Sesudah } \\
\cline { 2 - 6 } & \multicolumn{2}{c}{ n } & $\%$ & n & $\%$ \\
\hline Normal & 9 & 22,5 & 4 & 10,0 \\
Pre-Hipertensi & 11 & 27,5 & 10 & 25,0 \\
Hipertensi Stage I & 14 & 35,0 & 10 & 25,0 \\
Hipertensi Stage II & 5 & 12,5 & 12 & 30,0 \\
Hipertensi Stage III & 1 & 2,5 & 4 & 10,0 \\
\hline Total & 40 & 100,0 & 40 & 100,0 \\
\hline
\end{tabular}

Sumber: Data Primer 2019

Diatas menunjukkan bahwa pasien CKD sebelum melakukan hemodialisis dengan tekanan darah Normal yaitu sebanyak 9 orang $(22,5 \%)$, pasien CKD dengan tekanan darah Pre-Hipertensi sebanyak 11 orang $(27,5 \%)$, untuk pasien CKD dengan tekanan darah Hipertensi Stage I sebagian besar sampel yaitu sebanyak 14 orang (35\%), pasien CKD dengan tekanan darah Hipertensi Stage II yaitu sebanyak 5 orang $(12,5 \%)$, dan pada pasien CKD dengan tekanan darah Hipertensi Stage III yaitu hanya 1 orang $(2,5 \%)$. Sedangkan pasien
CKD setelah melakukan hemodialisis dengan tekanan darah Normal yaitu sebanyak 4 orang (10\%), pasien CKD dengan tekanan darah Pre-Hipertensi sebanyak 10 orang (25\%), untuk pasien CKD dengan tekanan darah Hipertensi Stage I sebagian besar sampel yaitu sebanyak 10 orang (25\%), pasien CKD dengan tekanan darah Hipertensi Stage II yaitu sebanyak 12 orang $(30 \%)$, dan pada pasien CKD dengan tekanan darah Hipertensi Stage III yaitu hanya 4 orang $(10 \%)$.

\section{Analisa Bivariat}

Tabel 4. Perbedaan Tekanan Darah Pasien CKD Sebelum dan Setelah Hemodialisis.

\begin{tabular}{|c|c|c|c|c|}
\hline & $\begin{array}{r}\text { Mean Rar } \\
\text { Rank }\end{array}$ & 1 & m of & Nilai \\
\hline TD SETELAH HD- & Negative Ranks 7 & & .50 & $73 \quad-3,091 \quad 0,002$ \\
\hline TD SEBELUM HD & Positive Ranks & 21 & 15.83 & 332.50 \\
\hline Ties & & & & \\
\hline Total & & & & \\
\hline
\end{tabular}

Sumber: Data Primer 2019 


\section{B. PEMBAHASAN}

\section{Perbedaan Tekanan Darah}

Tekanan Darah Sebelum Hemodialisa

Dari data responden yang diteliti berdasarkan sebelum melakukan tindakan hemodialisa diruang hemodialisa RSU GMIM Bethesda Tomohon. Hasil penelitian menunjukan bahwa dari total 40 responden (100\%) menunjukkan bahwa pasien CKD sebelum melakukan hemodialisis dengan tekanan darah Normal yaitu sebanyak 9 orang $(22,5 \%)$, pasien CKD dengan tekanan darah Pre-Hipertensi sebanyak 11 orang $(27,5 \%)$, untuk pasien CKD dengan tekanan darah Hipertensi Stage I sebagian besar sampel yaitu sebanyak 14 orang (35\%), pasien CKD dengan tekanan darah Hipertensi Stage II yaitu sebanyak 5 orang $(12,5 \%)$, dan pada pasien CKD dengan tekanan darah Hipertensi Stage III yaitu hanya 1 orang $(2,5 \%)$.

Menurut penelitian yang dilakukan oleh Kandarini (2012), tekanan darah penderita bisa normal saat memulai hemodialisis, kemudian meningkat setelah hemodialisis atau bisa juga sudah terjadi peningkatan tekanan darah pada saat memulai hemodialisis dan meningkat hingga akhir hemodialisis.

Penelitian yang dilakukan oleh (Rahmawati, 2016) menyatakan bahwa gangguan kardiovaskular merupakan faktor risiko akibat penyakit gagal ginjal kronik, diperkirakan 10-30 kali lebih tinggi pada klien hemodialisis dari pada populasi umum.

\section{Tekanan Darah Setelah Hemodialisa}

Hasil penelitian menunjukkan bahwa pasien CKD setelah melakukan hemodialisis dengan tekanan darah Normal yaitu sebanyak 4 orang (10\%), pasien CKD dengan tekanan darah Pre-Hipertensi sebanyak 10 orang (25\%), untuk pasien CKD dengan tekanan darah Hipertensi Stage I sebagian besar sampel yaitu sebanyak 10 orang (25\%), pasien CKD dengan tekanan darah Hipertensi Stage II yaitu sebanyak 12 orang (30\%), dan pada pasien CKD dengan tekanan darah Hipertensi Stage III yaitu hanya 4 orang $(10 \%)$.

Jika tekanan darah menurun, akan mengalami sebuah refleks yang akan menyebabkan peningkatan frekuensi jantung untuk mempertahankan tekanan darah (Sloane E., 2014). Menurut Sarifuddin (2012), faktor yang mempertahankan tekanan darah yaitu kekuatan memompa jantung, banyaknya darah yang beredar. Pemberian cairan seperti plasma atau garam akan menyebabkan tekanan darah naik.

\section{Perbedaan Tekanan Darah Pada Pasien CKD Sebelum dan Setelah Hemodialisis diruang HD.}

Hasil uji hipotesis yang dilakukan menggunakan uji statistik uji wilcoxon dengan tingkat kemaknaan $\alpha=$ 0,05 menunjukan bahwa nilai $\mathrm{Z}$ sebesar 3,091 dan $p$ sebesar $0,002 \quad(p \leq 0,05)$ sehingga adanya perbedaan tekanan darah pada pasien CKD sebelum dan setelah melakukan hemodialisis diruang hemodialisa RSU GMIM Bethesda Tomohon.

Terdapat hubungan yang signifikan antara kepatuhan hemodialisa dengan tekanan darah (Prasetya, 2015). Ketika tekanan darah sistolik melebihi 120 $\mathrm{mmHg}$ dan tekanan darah diastolic di atas $80 \mathrm{mmHg}$ dengan denyut 60-100 kali dalam satu menit, kerusakan dinding pembuluh darah akan terus bertambah dan ini bisa menyebabkan kebocoran saringan ginjal.

Tekanan darah pada pasien gagal ginjal kronis yang menjalani hemodialisa berpengaruh terhadap kualitas hidup pasien (Astrini, 2013). Hal ini sejalan dengan penelitian yang dilakukan oleh (Noradina, 2018)menyatakan bahwa ada pengaruh tindakan hemodialisa terhadap perubahan tekanan darah. Tekanan darah 
penderita bisa normal saat memulai hemodialisis, kemudian meningkat setelah hemodialisis. Atau bisa juga sudah terjadi peningkatan tekanan darah pada saat memulai hemodialisis dan meningkat hingga akhir hemodialisis (Kandarini 2012).

\section{KESIMPULAN}

Berdasarkan hasil penelitian terdapat ada Perbedaan Tekanan Darah Pada Pasien CKD Sebelum dan Setelah Hemodialisis di ruang HD.

\section{DAFTAR PUSTAKA}

Arif Muttaqin dan Kumala Sari. (2011). Asuhan Keperawatan Gangguan Sistem Perkemihan. Salemba Medika, Jakarta.

Comparison, T., Blood, O., Before, P., Renal, C., That, F., In, I., Hemodialysis, R., Hospital, A. A., Khoerunnisa, D., Afgani, A., \& Haribudiman, O. (2016). Perbandingan Tekanan Darah Sebelum dan Selama Hemodialisis pada Pasien Gagal Ginjal Kronis yang Menjalani Hemodialisis Rutin di RSUD Al-Ihsan Bandung Periode Bulan Maret Tahun 2016. Prosiding Pendidikan Dokter, 144(No.2), 557564.

Cahyaningsih, 2011. Hemodialisis (Cuci Darah) Panduan Praktis Perawatan Gagal Ginjal, Mitra Cendekian Press, Jogjakarta.

Diyono dan Sri, M. (2019). Buku Keperawatan Medikal Bedah Sistem Urologi. Andi Offset.

Ferdi, R. (2016). Tahun 2015. Cendekia Medika, $\quad 1(1), \quad 80-89$. https://jurnal.stikesalmaarif.ac.id/inde x.php/cendekia_medika/article/view/1 $7 / 11$

Hans Tandra. (2018). Dari Diabetes Menuju Ginjal. Penerbit PT Gramedia
Pustaka Utama

Musa, W., Kundre, R., \& Babakal, A. (2015). HUBUNGAN TINDAKAN HEMODIALISA DENGAN TINGKAT KECEMASAN KLIEN GAGAL GINJAL DI RUANGAN DAHLIA RSUP Prof Dr.R. KANDOU MANADO. Jurnal Keperawatan UNSRAT, 3(1), 109151.

Notoatmodjo. 2010. Metodologi Penelitian Kesehatan. Rineka Cipta. Jakarta

Noradina. (2018). Pengaruh tindakan hemodialisa terhadap perubahan tekanan darah pada klien gagal ginjal kronik di Rumah Sakit Imelda Medan tahun 2018. Jurnal Ilmiah Keperawatan Imelda, 4(2), 503509.

Rahman, M. T. S. A., Kaunang, T. M. D., \& Elim, C. (2016). Hubungan antara lama menjalani hemodialisis dengan kualitas hidup pasien yang menjalani hemodialisis di Unit Hemodialisis RSUP. Prof. Dr. R. D. Kandou Manado. E-CliniC, 4(1). https://doi.org/10.35790/ecl.4.1.201 6.10829

RISKESDAS. (2018). Laporan nasional RISKESDAS 2018. 20181228 Laporan Riskesdas 2018 Nasional.pdf Diakses pada tanggal 13 Maret 2019 jam 19.30 WIB.

Sarifuddin. (2009). Hubungan Tindakan Hemodialisa Dengan Perubahan Tekanan Darah Pasien Pasca Hemodialisis di Ruang Hemodialisa RSUD DR.M.M.

Setiadi. 2013. Konsep dan Praktik Penulisan Riset Keperawatan (ed.2). Graha Ilmu. Yogyakarta

Sloane E.(2014). Anatomi Dan Fisiologi Untuk Pemula.Jakarta:EGC.

Thalib, A. H. S. (2019). Gambaran Perubahan Tekanan Darah Pada Pasien Gagal Ginjal Kronik Yang Menjalani Terapi Hemodialisis Di 
Jurnal Keperawatan, Volume 9, No. 1, Februari 2021, (Hal. 56-62)

Ruang Hemodialisa Rumah Sakit TK.

II Pelamonia Makassar. (Jkg) Jurnal

Keperawatan Global, 4(2), 89-94.

https://doi.org/10.37341/jkg.v4i2.71 